\title{
Results of the experimental research of the heat-transfer jet pressure to the rock surface during thermal reaming of the borehole
}

\author{
Oleksii Voloshyn ${ }^{1 *}$, Iryna Potapchuk ${ }^{1}$, Oleksandr Zhevzhyk ${ }^{2}$, and Mykola Zhovtonoha ${ }^{3}$ \\ ${ }^{1}$ Institute of Geotechnical Mechanics under the National Academy of Science of Ukraine, Department \\ of Vibropneumatic Transport Systems and Complexes, 2a Simferopolska Str., 49005 Dnipro \\ ${ }^{2}$ Dnipropetrovsk National University of Railway Transport named after Academician V. Lazarian, \\ Department of Thermal Engineering, 2 Lazariana Str., 49010 Dnipro, Ukraine \\ ${ }^{3}$ Dnipropetrovsk National University of Railway Transport named after Academician V. Lazarian, \\ Department of Accounting, Auditing and Intellectual Property, 2 Lazariana Str., 49010 Dnipro, \\ Ukraine
}

\begin{abstract}
The performed analysis of scientific sources confirms the existence of a small number of publications devoted to the experimental research of the gasdynamics and plasmodynamics of jets used as a heattransfer medium in the thermal methods of mine rocks destruction. There are almost no experimental and theoretical publications related to the multiple-jet plasmotrons research. The expediency of own experimental researches performing has been substantiated concerning the lateral inflow of heat-transfer medium high-speed jets on the borehole surface. An experimental research has been made of the interaction between the heattransfer medium high-speed jets and the surface of the borehole imitated by the through duct. The further prospects of this work are the following: to determine the gas velocity along the lateral surface of the through duct and the value of the heating capacity coefficient from the heat-transfer medium to the lateral surface of the through duct, which imitates the rock surface in the borehole. These parameters are required for creating a mathematical model of the brittle destruction of rocks.
\end{abstract}

\section{Introduction}

Taking into account productivity and expenditures for various methods of the borehole drilling and reaming realization, thermal methods of rock destruction are of the most interest.

The relevance of application of thermal methods for rock destruction is based on the wide range of facilities for realization of the heating or cooling processes of rock.

Forms of thermal influence on the rock have the unified physical basis, namely, change of power connections potential. Tensions of thermal expansion of rock minerals are proportional to the thermal expansion coefficient of minerals, Young's modulus and heating temperature. Since Young's modulus and thermal expansion coefficient of rock

\footnotetext{
* Corresponding author: OIVoloshyn1951@nas.gov.ua
} 
minerals take different values, while heating inside the rock minerals besides tensions, predefined by the emergence of temperature gradient, the structural thermal tensions appear, that reach maximal values on the edges of mineral grains. Therefore most of thermal rock destruction products detach from the rock mass along the grain edges of minerals.

In the cases of application of thermal methods of rock destruction the destruction products detach from the rock mass under the influence of the shear and tensile thermal stresses.

It is known that the strength limit for shearing and stretching is approximately $7-10$ times less than the strength limit for the compression. Therefore a thermal method of rock destruction is the most energy saving method of destruction.

While temperature increasing in a heating area along with the strength and aggregate hardness decreasing there is a reduction of rock fragility emerges that allows to use the thermal methods of rock destruction effectively not only in the processes of the borehole drilling but also in the processes of the boreholes reaming [1].

Most effective amid the processes of the borehole reaming are the thermal ones, in particular with application of the gas jet heating of rock with usage of arc electrical discharge.

Plasma burners have some advantages:

- widened adjustment range of thermal parameters and concentration of the jet power [2];

- diminished amount of hazardous gases emission;

- simplified system of the burners automation;

- fissure propagation at significant depth of the rocks in the process of their thermal destruction;

- higher values of the heat transfer coefficient and specific heat flux from the heattransfer medium to the borehole surface.

Due to high velocity of the torch movement in a borehole an average velocity change of its temperature is provided for the range of $3000-5000{ }^{\circ} \mathrm{C} / \mathrm{s}$.

It should be noted that efficiency of thermal fragile rock destruction increases due to rock hardness augmentation and expenditures of this process realization tend to diminish. The highest efficiency of thermal method for rock destruction is reached in the borehole reaming process in a monolithic enough and well-drillable rock mass.

The analysis of scientific sources testifies that for the known devices with an arc electrical discharge for rock destruction the ranges of operating performance of thermal tools, effective modes of heating, mechanical loading and fragile rock destruction were determined, mostly, in an experimental manner. Prevailing majority of the known experimental investigations concern the determination of time and temperature values of rock destruction [ $3-9]$. Few publications devoted to the question of the experimental investigation of gas dynamics and plasma dynamics of the jets, that are used as a heat transfer medium in the thermal methods of rock destruction [10,11 - 13].

The reference [10] presents average values of the heat transfer coefficient obtained by means of experimental investigation from the heat transfer medium to the rock surface, however insufficient attention is paid to the gas dynamics and interaction of the heat transfer medium jet with the borehole surface.

The references $[11,12]$ provide an information about velocity of the heat transfer medium at the nozzle outlet and its value gains up to $120 \mathrm{~m} / \mathrm{s}$, that could be compared with velocity of plasma flow at the nozzle outlet of plasmatron, however as a heat transfer medium an incompressible liquid is used. It makes impossible to use the results of the experimental investigation for determination of the heat transfer coefficient from plasma jet to the rock surface.

In the reference [14] for fragile rock destruction the high-speed (Mach number within 
the range of $2-5)$ and high temperature $\left(300-1100{ }^{\circ} \mathrm{C}\right)$ jets of the heat transfer medium were used. However the outflow of the heat transfer medium from a nozzle took place in the pulsatile mode, and efficiency of rock destruction depended on gauge pressure of the jet on the surface of the borehole, that was at the range of 5-20 MPa.

The device for creation of reservoir cavity in rocky ragstones is well-known [15]. The air (plasma) heated by plasmatron flows out through its nozzle along the axis of the borehole on the working face.

Among the flaws of device it should be noted that a plasma torch flowing along the axis of the borehole not enough effectively influences on the borehole surface during its reaming.

Well-known the device for electrical arc plasma drilling that contains flat nozzles located at interelectrode intervals that cross, and incorporated by the central channel of plasmatron is well-known [16].

Among the flaws of device it should be noted that flat nozzles are located on the end face of plasmatron that is why plasma torches spreading along the axis of the borehole not enough effectively influence on the borehole surface during its reaming.

Angular plasmatron that contains channel of plasma stream formation inclined with respect to the frame axis that allows to increase efficiency of thermal energy transmission inside the rock and mechanical influence of plasma stream on the borehole surface that ultimately increases the productivity of the borehole reaming in a zone of plasma stream channel forming is known [17].

Among the flaws of device it should be noted a necessity to revolve the plasmatron around its longitudinal axis in order to ream an inner surface of the borehole at a certain level.

A task to be decided in the present publication is the plasmatron creation that able to process to ream all inner surface of the borehole at a certain level without the plasmatron rotation around its longitudinal axis with the effective transmission of thermal energy inside a mountain the rock and mechanical influence of plasma stream on the borehole surface.

For such a plasmatron axes of plasma stream channels formation are inclined with respect to the frame axis in different directions at the same acute angles.

The features of the known experimental researches allow to determine velocity of the heat transfer medium on the surface of the borehole and values of the heat transfer coefficient only for the conditions indicated in those publications.

An efficiency of thermal methods of rock destruction is defined by specific heat flux that is transferred from the heat transfer medium to the rock surface.

Specific heat flux can be augmented due to increasing of the heat transfer medium temperature or heat transfer coefficient.

In case of rock destruction in the spallation mode, i.e. in case of thermal reaming of the boreholes, an increasing of the heat transfer medium temperature is inexpedient, as it can lead to the rock melting. In this case it is necessary to increase the heat transfer coefficient from the heat transfer medium to the rock surface due to the augmentation of the mass velocity of the heat transfer medium, i.e. increasing of the heat transfer medium rate and velocity. Thus, application of the high-speed jets of the heat transfer medium seems to be prospective in the processes of fragile rock destruction.

As the known results of experimental researches dissatisfy to the decision of tasks of the current work, fulfilment of own experimental research of the interaction of high-speed heat transfer medium jets with the borehole surface is necessary.

\section{Methods}

Experimental research of the interaction of high-speed jets of the heat transfer medium with the borehole surface is executed as a lateral surface of the cross duct imitated the rock 
surface in a borehole.

The scheme of the heat-transfer medium stream interaction with the side surface of the cross duct is shown in Fig. 1.

Compressed air from a compressor through the gate and regulative valves and prechamber flows through the air duct directly to the nozzle. A model that imitates the rock inside the borehole is executed as a cross duct channel (Fig. 2).



Fig. 1. The scheme of the heat-transfer medium stream interaction with the side surface of the cross duct.

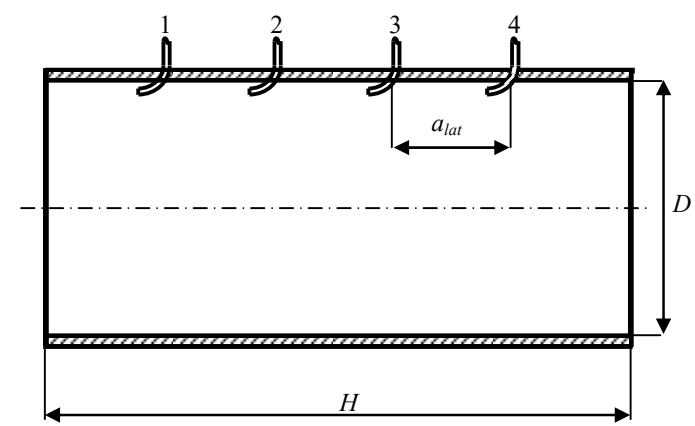

Fig. 2. The disposal of the drainage orifices in the cross duct; $1-4$-drainage orifices; $a_{\text {lat }}$ - distance from the drainage orifices to the end of the cross duct; $\mathrm{H}$ - cross duct length; D - inner diameter of the cross duct.

For pressure determination in the air duct and prechamber the deformation standard manometers of 1227 model were used with a provisional scale of the MO type. The upper limit of measurement of the standard manometers is $1.6 \mathrm{MPa}$. The accuracy class of devices is 0.15 [18].

The essence of experimental investigation consisted of measurement of pressure on the lateral surface of the cross duct at the air jet impingement on the lateral surface. For this purpose the drainage orifices in the cross duct are made that connected by impulse tubes to the recording manometers [18].

The values of pressure on the lateral surface of the cross duct obtained during experimental investigation are necessary for determination of the gas velocity along the lateral surface of the cross duct what makes possible to determine the heat transfer coefficient from gas that imitates the heat transfer medium, to the lateral surface of the cross duct that imitates the rock surface in the borehole.

Drainage orifices $0.8 \mathrm{~mm}$ in diameter are executed in the normal line direction to the axis of the cross duct. The copper tubes of total pressure were set in the drainage orifices.

The edges of tubes are located on $0.3 \mathrm{~mm}$ above the inner surface of the duct and turned to the flow that impinges the duct, for measurement possibility of the total pressure of flow that enters the duct. For the velocities of flow less than $M<2.3$ the error of total pressure measurement by a copper tube does not exceed $1 \%$ [19].

Rubber impulse tubes $2 \mathrm{~mm}$ in diameter from the drainage orifices of the cross duct brought to the recording manometers. The maximum error of manometers measurement equals $0.5 \%$ of the maximal pressure value that is measured [19]. Accuracy estimation of gauge pressure measurement as well as damping period of the wave processes in tubes were 
provided in accordance with well-known methodology [20].

Thermophysical and mechanical properties of mediums and materials that were used during experimental research were taken in accordance with [21].

An experiment for interaction of the gas jet with the lateral surface of the cross duct involved values as follows:

- nozzle outlet diameter $\left(d_{0}\right)-0.016 \mathrm{~m}$;

- nozzle length $\left(L_{n o z}\right)-0.016 \mathrm{~m}$;

- inner diameter of the cross duct $(D)-0.08 \mathrm{~m}$;

- cross duct length $(H)-0.15 \mathrm{~m}$;

- distance between drainage orifices along the side surface of the cross duct $\left(a_{\text {lat }}\right)$ $0.030 \mathrm{~m}$;

- relative distance from the outlet orifice plain to the inlet cross duct plain $\left(\bar{h}=h / d_{0}\right)-$ $12,16,20,28$;

- absolute air pressure at the nozzle inlet $P_{n o z}=1.1 ; 1.5 ; 1.7 ; 1.9 ; 2.1 \mathrm{MPa}$;

- an angle between the axis of nozzle and axis of the cross duct $\phi=30^{\circ}, 45^{\circ}$;

- mach number at the nozzle outlet $\left(M_{0}\right)-1.0$.

The geometrical parameters of the cross duct and the nozzle are adopted in accordance with geometrical similarity to the technological and processing parameters of plasmatron and diameter of boreholes before the beginning of the thermal reaming process.

In more detail the methodology of experimental research and the scheme of the experimental set-up are described in [22].

An imitation of the plasma jet by means of air is absolutely acceptable, because an ionization level of the low temperature plasma used as the heat transfer medium in the processes of the rock thermal destruction does not exceed $1 \%$.

\section{Results and discussion}

In Fig. 3 dependence of gauge pressure on the side surface of the cross duct, i.e. on the rock surface on absolute air pressure at the nozzle inlet and relative distance from the outlet orifice plain to the inlet cross duct plain for different values of an angle between the axis of nozzle and axis of the cross duct is shown.

Comparison of pressure values of the air stream on the inner surface of the cross duct a allows to make a conclusion that for other equal conditions pressure on the inner surface of the cross duct increases with the augmentation of pressure at the nozzle inlet that testifies an adequacy of measurement results.

Fig. 3 shows that increasing of pressure at the nozzle inlet causes an augmentation of pressure, and, accordingly, velocity of the heat-transfer medium on the rock surface.

In a point 1 air stream pressure on the surface of the cross duct reaches highest value since point 1 is the nearest one to the intersection of the stream axis with the surface of the cross duct.

Increasing of the distance from the outlet orifice plain to the inlet cross duct plain pressure on the inner surface of the cross duct diminishes and, accordingly, diminishes air velocity along the side surface of the cross duct.

Pressure distribution along the surface of the cross duct subjects to the nonlinear relationship.

Thus, the results of the experimental investigation allow to make a conclusion that the application of high-speed plasma jets and, actually, plasmatron as the thermal tool for rock destruction is a prospective direction of the scientific research. 

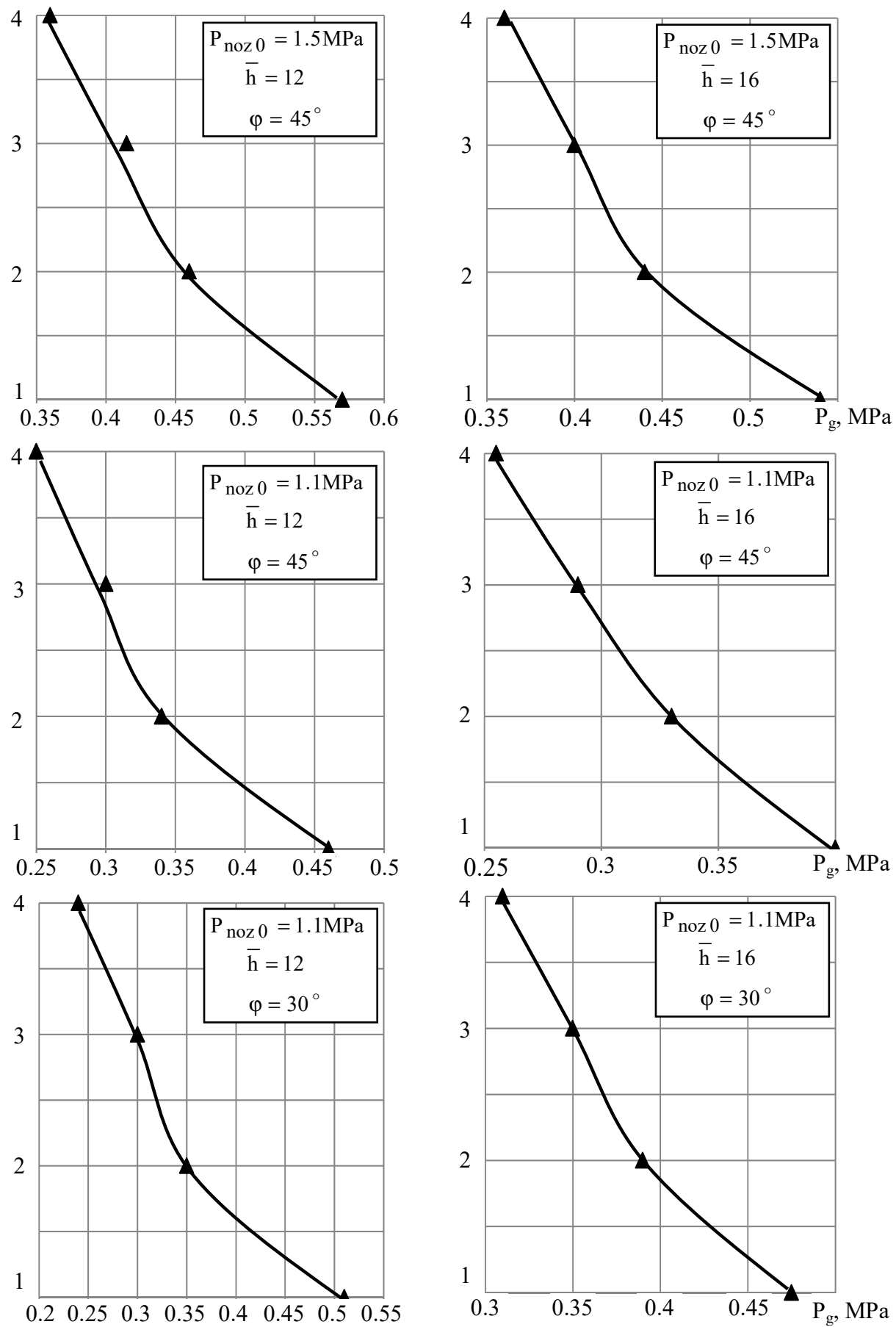

Fig. 3. Dependence of gauge pressure $\left(P_{g}\right)$ of the heat-transfer medium on the side surface of the cross duct on absolute air pressure at the nozzle inlet and relative distance from the outlet orifice plain to the inlet cross duct plain. 


\section{Conclusions}

The analysis of publications that proves the presence of small amount of publications devoted to the experimental research of gas dynamics and plasma dynamics of the jets that are in application as a heat transfer medium in the thermal methods of rock destruction.

The motivation of the fulfilment of own experimental researches of interaction of highspeed heat transfer medium jets with the inner surface of the borehole is made.

The experimental research of interaction of high-speed heat transfer medium jets with the inner surface of the borehole is made as a lateral inner surface of the cross duct imitated the rock surface in a borehole.

The further prospects of this work are next: the determination of gas velocity along the lateral surface of the cross duct and the value of the heat transfer coefficient from the heat transfer medium to the lateral surface of the cross duct that imitates the rock surface in the borehole.

Authors wish to gratitude to V.P. Teplyi, the Chief Project Designer in Department of Vibropneumatic Transport Systems and Complexes and to S.V. Shniakin, Principal Engineer in the Department of Vibropneumatic Transport Systems and Complexes of Institute of Geotechnical Mechanics named by M.S. Poliakov of National Academy of Sciences of Ukraine for their valuable support of the experimental investigation. Authors also wish to gratitude to L.T. Kholiavchenko, Ph.D, Senior Researcher in Department of Rock Breaking Problems Institute of Geotechnical Mechanics named by M.S. Poliakov for his valuable advices and suggestions relating to the experimental investigation.

\section{References}

1. Dmitriev, A.P., Goncharov, S.A., \& Zilbershmidt, M.G. (2011). Contemporary problems of selective and energy saving rock destruction. Gornyy informatsionno-analiticheskiy byulleten, (1), 169-184.

2. Bulat A., Voloshyn, O., \& Zhevzhik, O. (2013). Plasma reactor for thermochemical preparation of coal-air mixture before its burning in the furnaces. Annual Scientific-Technical Collection Mining of Mineral Deposits, 39-44. https://doi.org/10.1201/b16354-9

3. Hoser, D., \& von Rohr, P.R. (2018). Experimental heat transfer study of confined flame jet impinging on a flat surface. Experimental Thermal and Fluid Science, (91), 166-174. http://dx.doi.org/10.1016/j.expthermflusci.2017.10.014

4. Kant, M., Rossi, E., Madonna, C., Höser, D., \& von Rohr, P.R. (2017). A theory on thermal spalling of rocks with a focus on thermal spallation drilling. Journal of Geophysical Research: Solid Earth, 122(3), 1805-1815. http://dx.doi.org/10.1002/2016JB013800

5. Kant, M.A., Rossi, E., Duss, J., Amann, F., Saar, M.O., \& von Rohr, P.R. (2018). Demonstration of thermal borehole enlargement to facilitate controlled reservoir engineering for deep geothermal, oil or gas systems. Applied Energy, (212), 1501-1509. http://dx.doi.org/10.1016/j.apenergy.2018.01.009

6. Rauenzahn, R., \& Tester, J. (1989). Rock failure mechanisms of flame-jet thermal spallation drilling theory and experimental testing. International Journal of Rock Mechanics and Mining Sciences \& Geomechanics Abstracts, 26(5), 381-399. http://dx.doi.org/10.1016/01489062(89)90935-2

7. Rauenzahn, R.M., \& Tester, J.W. (1991). Numerical simulation and field testing of flame-jet thermal spallation drilling - 2. Experimental verification. International Journal of Heat and Mass Transfer, 34(3), 809-818. http://dx.doi.org/10.1016/0017-9310(91)90127-Z

8. Wilkinson, M.A., \& Tester, J.W. (1993). Experimental measurement of surface temperatures during flame-jet induced thermal spallation. Rock Mechanics and Rock Engineering, 26(1), 29-62. http://dx.doi.org/10.1007/BF01019868 
9. Yan, C., Deng, J., Yu, B., Li, W., Chen, Z., Hu, L., \& Li, Y. (2014). Borehole stability in hightemperature formations. Rock Mechanics and Rock Engineering, 47(6), 2199-2209. http://dx.doi.org/10.1007/s00603-013-0496-2

10. Yanchenko, G.A., Zharovkin, A.V., \& Bulycheva, E.S. (2003). About the parameters of the thermal reaming of blastholes in the ferrous quartzites of Kostomuksha GOK at the use of emulsive explosives of "Sibirit-1200" type. Gornyy informatsionno-analiticheskiy byulleten', (9), $1-5$.

11. Babayan, E.V., \& Chernenko, A.V. (2016). Inzhenerne raschety pri burenii. Moskva: InfraInzheneriya.

12. Osipov, P.F., \& Skryabin, G.F. (2001). Optimizatsiya rezhimov bureniya gidromonitornymi sharoshechnymi dolotami. Yaroslavl': Medium-Press.

13. Gulin, V.V., \& Ustimenko, T.A. (2014). Designing of generators of impulse jets on the basis of structural synthesis. Vostochno-Yevropeyskiy zhurnal peredovykh tekhnologiy, 4(7), 38-45.

14. Plugin, A.I. (2001). Sposob obrazovaniya skvazhin i vyrabotok v geologicheskikh strukturakh. Patent No. 2168598, Russian Federation.

15. Bulat, A.F., Makeiev, S.Yu., Osinnii, V.Ya., \& Yemelianenko, V.I. (2014). Ustanovka stvorennia rezervuarnoi porozhnyny $v$ mitsnykh skalnykh porodakh. Patent No. 94670, Ukraine.

16. Gizatullin, S.A., \& Dautov, G.Yu. (1997). Ustanovka elektrodugovogo plazmobura. Patent No. 2100602, Russian Federation.

17. Lazhenitsyn, A.I., \& Smirnov, A.A. (2012). Plazmotron uglovoy. Patent No. 2464746, Russian Federation.

18. Mulyev, Yu.V. (2003). Manometry. Moskva: MEI.

19. Andreev, V.V., Chekhlova, T.K., \& Chuprov, D.V. (2008) Izmereniya i pribory v fizicheskom eksperimente. Moskva: RUDN.

20. Tarasova, V.N., Malynovskyi, A.S., \& Rybak, M.F. (2006). Metrolohiia, standartyzatsiia $i$ sertyfikatsiia. Kyiv: Tsentr navchalnoi literatury.

21. Bogoslovskiy, S.V. (2001). Fizicheskie svoystva gazov i zhidkostey. Sankt-Petersburg: SPbGUAP.

22. Voloshyn, O.I., Potapchuk, I.Yu., \& Zhevzhyk, O.V. (2018). Influence of the heat-transfer stream pressure on the surface of the rock in a process of the thermal reaming of the borehole. Naukovyi Visnyk Natsionalnoho Hirnychoho Universytetu, 164(2), 53-59. http://dx.doi.org/10.29202/nvngu/2018-2/6 